\title{
Role of Helicobacter pylori-induced Antralization in Gastric Carcinogenesis and its Implications in Clinical Practice
}

\author{
Zhi-Ning Ye\#, Ran Zhang\#, Xing-Xiang He and Harry Hua-Xiang Xia* \\ Department of Gastroenterology, the First Affiliated Hospital of Guangdong Pharmaceutical University, Guangzhou, Guangdong \\ Province, P. R. China; " Contributed equally to the manuscript and should be listed as shared first author.
}

\begin{abstract}
The aim of this article was to review the roles of Helicobacter pylori-induced antralization in gastric carcinogenesis and its implications in clinical practice. A search of PubMed/PubMed Central, Web of Science, and China National Knowledge Infrastructure was performed in December 2018 to retrieve all literature related to antralization (or antralisation), pyloric (or pseudopyloric) glands, pyloric (or pseudopyloric) metaplasia, or pyloric (or pseudopyloric) gland metaplasia, and spasmolytic polypeptide-expressing metaplasia (or SPEM). Among the synonyms, antralization and SPEM, which are derived in the same mechanisms at the molecular, cellular and tissue levels, are more commonly used in recent studies. Antralization (or SPEM) is associated with $H$. pylori infection, atrophic gastritis and intestinal metaplasia, while $H$. pylori eradication may reverse antralization. It is proposed that $H$. pylori infection leads to inflammation in the gastric mucosa and apoptosis of the epithelial cells of the proximal stomach, including gastric incisura, body and fundus. The stem cells proliferate and transform into mucous cells and form antral-type mucosa (i.e. antralization). Subsequently, H. pylori-induced antralization, if not controlled, may develop into atrophic gastritis, intestinal metaplasia, dysplasia, and early intestinal-type gastric cancer. Although many biomarkers, including the spasmolytic polypeptide and mucin 6 , are specifically expressed in the gastric mucosa with antralization, none of them are evaluated for the clinical diagnosis of antralization. $H$. pyloriinduced antralization (or SPEM) is believed to be an initiating and reversible stage of gastric carcinogenesis. Identification of antralization would help make an early intervention to cease or even reverse the process toward the development of gastric cancer. Currently, the "gold standard" for diagnosing antralization is pathology, which is invasive and time consuming. A non-invasive and convenient method that accurately and specifically diagnoses antralization is urgently required.
\end{abstract}

Introduction

According to the latest global cancer data released by the World

Keywords: Antralization; Helicobacter pylori; Gastritis; Precancerous lesions; Gastric carcinogenesis.

Abbreviations: CagA, cytotoxin-associated gene A; CDX2, caudal-related homeobox transcription factor 2; HtrA, high temperature requirement A; ME-NBI, magnifying endoscopy with narrow band imaging; MUC6, mucin 6; NKX6.1, NK6 homeobox 1; PAX6, paired box 6; PDX1, pancreatic duodenal homeobox 1; PGI, pepsinogen I; SCF, stem cell factor; SPEM, spasmolytic polypeptide-expressing metaplasia; STAT3, signal transduction and activator of transcription 3; TFF2, trefoil factor 2; T4SS, a type IV secretion system encoded in the cag-pathogenicity island; VacA, vacuolating cytotoxin A; WHO, World Health Organization.

Received: April 25, 2019; Revised: August 06, 2019; Accepted: August 07, 2019

*Correspondence to: Harry Hua-Xiang Xia, Department of Gastroenterology, the First Affiliated Hospital of Guangdong Pharmaceutical University, Guangzhou 510080, Guangdong Province, China. E-mail: xiaharry@hotmail.com

How to cite this article: Ye ZN, Zhang R, He XX, Xia HHX. Role of Helicobacter pylori-induced Antralization in Gastric Carcinogenesis and its Implications in Clinical Practice. Exploratory Research and Hypothesis in Medicine 2019;4(3):43-51. doi: 10.14218/ERHM.2019.00009.
Health Organization (commonly known as WHO), gastric cancer was responsible for over 1,000,000 new cases in 2018 and an estimated 783,000 deaths (equating to 1 in every 12 deaths globally), making it the fifth most frequently diagnosed cancer and the third leading cause of cancer death. ${ }^{1}$ It has been established by WHO that Helicobacter pylori infection is a class I carcinogen of gastric cancer, and contributes to nearly $90 \%$ of non-cardiac cancer cases. ${ }^{2}$ Although the incidence of gastric cancer has declined over the past recent decades, following due improvements in the environment and control of $H$. pylori infection in clinical practice, gastric cancer is still a major threat to human health.

Currently, there are still no curative therapeutic modalities for advanced gastric cancer, and screening of early gastric cancer is critical for improvement of its outcomes. Histologically, there are two major types of gastric cancer: intestinal-type and diffusetype. ${ }^{3}$ The international consensus on the prevention and treatment of gastric cancer recommends the detection and monitoring of precancerous lesions, including atrophic gastritis, intestinal metaplasia, and dysplasia and diagnosis of early gastric cancer, ${ }^{4}$ which is virtually based on the theory on intestinal-type gastric cancer pub- 
lished by Correa et al. In 1990, Correa and colleagues ${ }^{5}$ proposed a model of gastric carcinogenesis, ${ }^{5}$ typically for intestinal-type gastric cancer, with the following sequential stages: from normal gastric mucosa to acute and chronic superficial gastritis, atrophic gastritis, intestinal metaplasia, dysplasia, and subsequently early gastric cancer.

Correa's cascade of gastric carcinogenesis is now widely accepted, with $H$. pylori infection being recognized as the major initiating factor in the process. Eradication of $H$. pylori infection is shown to reduce the risk of developing gastric cancer, and thus considered to be a strategy to prevent gastric cancer. ${ }^{3}$ However, the preventive efficacy is limited in the presence of precancerous lesions, such as atrophic gastritis, intestinal metaplasia, and dysplasia. ${ }^{6}$ In fact, there is no consensus on whether atrophic gastritis and intestinal metaplasia are reversible, although it is generally agreed that dysplasia is irreversible. Whereas some studies have demonstrated that $H$. pylori eradication decreases the degree of atrophic gastritis and intestinal metaplasia, others have failed to confirm the findings. ${ }^{7-15}$ Therefore, there is not sufficient evidence indicating the reversibility of atrophic gastritis and intestinal metaplasia, and identification of a reversible pathological change that occurs immediately prior to these precancerous lesions is crucial to developing an early intervention strategy that will cease or even reverse the development of gastric cancer.

In 1998, with the in-depth investigation of gastric mucosal histology, Xia et al..$^{16}$ observed that $H$. pylori infection was associated the presence of antral-type mucosa in gastric incisura, which was further associated with atrophic gastritis and intestinal metaplasia. They coined a term "antralization" for this histological change. In addition, the authors reported later that antralization was present at the edge of proximal gastric ulcers and disappeared after H. pylori eradication in a substantial proportion of patients. ${ }^{17}$ In 1999 , Schmidt et al. ${ }^{18}$ reported a metaplasia lineage in the stomach that specifically expresses spasmolytic polypeptide (also called trefoil factor 2 or TFF2) that is associated with gastric cancer. The authors defined this lineage as spasmolytic polypeptide-expressing metaplasia (SPEM), which is believed to share the same histological origin, i.e. they are derived in the same mechanisms at the molecular, cellular and tissue levels. It is hypothesized that $H$. pyloriinduced antralization, or SPEM, may play a key role in the process of gastric carcinogenesis. More importantly, it may be a reversible point prior to the precancerous lesions after eradication of $H$. pylori infection, ${ }^{17}$ which may subsequently slow down, cease, or even reverse the process of gastric carcinogenesis; although, convincing evidence is required to prove this hypothesis.

The aim of this article was to review the role of $H$. pyloriinduced antralization (or SPEM), in gastric carcinogenesis, specifically for intestinal-type gastric cancer, and its implications in clinical practice. In this review, we use "antralization", where appropriate, to emphasize the carcinogenic roles and clinical implications of this histological change, as we believe that antralization is more suitable to specifically describe the transition of the specialized glands in the gastric body or at the body-antrum junction by mucous-secreting glands.

\section{Literature search}

A search of PubMed/PubMed Central, Web of Science, and China National Knowledge Infrastructure was performed in December 2018 to retrieve all literature related to the terms antralization (or antralisation), pyloric (or pseudopyloric) glands, pyloric (or pseudopyloric) metaplasia, pyloric (or pseudopyloric) gland metaplasia, and SPEM. As the present review mainly focuses on antralization and SPEM, we tried to include articles with the highest relevance to the topic of this review. As a result, a total of 40 articles were identified, 13 on antralization (or antralisation), 9 on pyloric (or pseudopyloric) glands, pyloric (or pseudopyloric) metaplasia, pyloric (or pseudopyloric gland) metaplasia, and 18 on SPEM.

\section{Antralization and its synonymous terms}

Normal gastric biopsy mucosa can be divided into three types: antral-type (also called pyloric type), body-type (also called fundic, acid-secreting or oxyntic type), and transitional-type (also called junctional or intermediate type). ${ }^{16,17,19,20}$ Antral-type mucosa is characterized by coiled and branching antral glands, which are arranged by mucous cells scattered with endocrine cells (mainly $G$ cells and D cells), and a few parietal cells (Fig. 1a). The glands in body-type mucosa are straight tubes, forming parietal cells that produce hydrochloric acid, and there are scattered mucous cells in their upper portion and mainly endocrine cells in their lower portion (Fig. 1b). Transitional-type mucosa is a mixture of structural characteristics and cell types found in the antral and body type mucosa. "Antralization", which was first officially coined in 1998 by Xia et al., ${ }^{16,17,20}$ refers to the change of gastric mucosa from the transitional or even body-type to the antral-type, especially in the gastric incisura angularis ${ }^{16}$ (Fig. 1c).

This histological change can also be observed at the endocrine level. Rubio et al. ${ }^{19}$ found that the positive rate of gastrinproducing cells in the mucosa with antralization in the incisura was similar to that in the gastric mucosa of the antrum, but significantly higher than that in the transitional and body-type mucosa in the incisura, and confirmed that antralization was a form of transformation or metaplasia. Indeed, Nookaew et al. ${ }^{21}$ found that antralization of the corpus mucosa with atrophy was characterized by increased gastrin expression and decreased expression of corpus-related genes, such as those associated with acid production, energy metabolism, and blood clotting. In fact, over the past 5 decades prior to the introduction of antralization or SPEM, a few terms, including pyloric/pseudopyloric glands, pyloric/pseudopyloric metaplasia, and pyloric/pseudopyloric gland metaplasia, have been used to describe the change. ${ }^{22-26}$

As early as in 1949, Hebbel et al. ${ }^{22}$ described the presence of pseudopyloric glands in the gastric mucosa of some patients with gastritis and pointed out that there were pseudopyloric glands near the healed gastric ulcer. Similar to true pyloric glands, pseudopyloric glands consist of two different types of cells: mucin-containing cells, which lack the characteristics of typical mucous cells but with characteristics between mucous and serous cells, and endocrine cells, which are mainly composed of enterochromaffin cells, pancreatic A cell-like cells, and A cell-like cells (a subtype of gastric A cells). ${ }^{27}$ The same phenomenon was found in animal stomach tissue. Hunt ${ }^{28}$ found that the ulcerated area of the gastric fundus mucosa was first covered by regenerated epithelium containing mucous glands, which are pseudopyloric glands. Van der Gaag also found antral-like tissue in the nonantral region of canine stomach and found that it was associated with gastritis. ${ }^{29}$ Whitehead et al. ${ }^{30}$ analyzed more than 2,500 biopsy specimens and found that pseudopyloric gland metaplasia often occurred in patients with atrophic gastritis, which may be reversible. These studies demonstrate that pyloric/pseudopyloric glands, pyloric/ pseudopyloric metaplasia, and pyloric/pseudopyloric gland metaplasia are associated with chronic gastric injuries. However, these studies are also limited by their observational nature, with little 

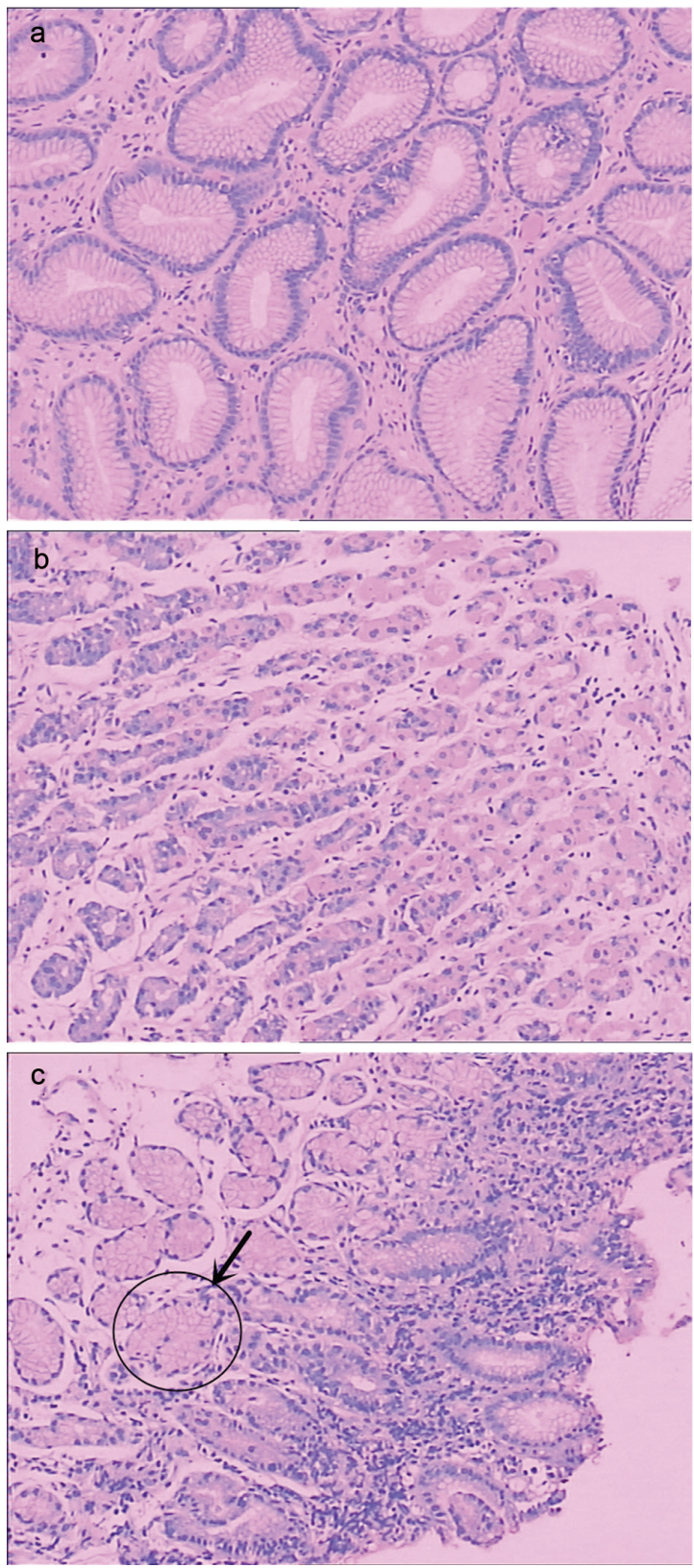

Fig. 1. Gastric glands and antralization. (a) Pyloric glands under light microscope, $\times 100$, H\&E staining. (b) Fundus glands under light microscope, $\times 100, \mathrm{H} \& \mathrm{E}$ staining. (c) Antralization (arrow) in the gastric incisura under light microscope, $\times 100, H \& E$ staining. The pictures were provided by Department of Pathology, the First Affiliated Hospital of Guangdong Pharmaceutical University, Guangzhou, China. H\&E, hematoxylin and eosin.

exploration on the etiological and pathological significance and the underlying molecular mechanisms.

In 1999, Schmidt et al. ${ }^{18}$ reported SPEM and its association with gastric cancer. Then, Yamaguchi et al. ${ }^{31}$ identified SPEM in remnant gastric cancer and considered SPEM as a potential precursor lesion of gastric cancer. Current studies have shown that SPEM is associated with the occurrence of gastric cancer, and it has been proposed that SPEM may develop into intestinal metaplasia, then further into gastric cancer or directly into gastric cancer. However, this hypothesis still needs to be confirmed. ${ }^{32}$

Although all the synonymous terms described above are believed to share the same histological origin, i.e. they are derived in the same mechanisms at the molecular, cellular and tissue levels. The terms antralization and SPEM are more commonly used in recent years in various extensive clinical and experimental studies. To emphasize the carcinogenic roles and clinical implications of this histological change, we use "antralization", where appropriate, in this review, as we believe that the term antralization is more suitable to specifically describe the transition of the specialized glands in the gastric body or at the body-antrum junction by mucous-secreting glands.

Role of $\boldsymbol{H}$. pylori-induced antralization (or SPEM) in gastric carcinogenesis

H. pylori-induced antralization (or SPEM) is believed to play an important role in the development of intestinal-type gastric carcinoma, and thus is a critical step of the Correa's cascade. Several mechanisms are proposed.

Colonization of $H$. pylori in the gastric mucosa is a key step in the occurrence of antralization. However, whether or not antralization, and subsequent precancerous lesions, occurs largely depends on the presence of virulence factors of $H$. pylori, including CagA (an effector protein encoded by the cytotoxin-associated gene A), T4SS (a type IV secretion system encoded in the cag-pathogenicity island), VacA (vacuolating cytotoxin A), $\gamma$-glutamyl transpeptidase, high temperature requirement A (HtrA, a serine protease), and cholesterol glycosyl-transferase, etc. ${ }^{33}$ A recent study found that $H$. pylori penetrated deep within the body glands in mice with SPEM induced by high-dose tamoxifen, by combining its adhesin, SabA, with the SPEM-related sialyl-Lewis X, and that $H$. pylori colonization further strengthened the expansion of SPEM in the gastric mucosa, which progressed to more serious lesions. ${ }^{34}$

After $H$. pylori colonization, a series of protective reactions occur in the gastric mucosa. Generally, there are two kinds of protective reactions, including superficial reaction, which occurs after acute mucosal injury, and protects the stomach from the endogenous acid and glandular reaction that occurs during chronic infection and leads to the loss or damage of parietal cells and subsequent glandular regeneration, and adapts to the loss or damage of the gastric acid source. ${ }^{35}$

It has been postulated that both apoptosis and cell proliferation increase in $H$. pylori-induced gastritis. ${ }^{29}$ The increased apoptosis and proliferation in $H$. pylori infection are regulated by over-expression of tumor suppressor genes, such as $p 53$, bax or bak, and down-expression of the oncogenes, such as $b c l-2$, to maintain their balance. However, when precancerous lesions such as atrophic gastritis, intestinal metaplasia and dysplasia develop, expression of antiapototic genes is increased and pro-apoptotic genes become decreased, resulting in a decrease in apoptosis, whereas proliferation remains increased. Therefore, the balance between apoptosis and proliferation is altered (i.e. in favor of proliferation), thereby increasing the risk of developing gastric carcinoma. ${ }^{36-38}$

Indeed, Xia et al. ${ }^{39}$ found that apoptosis and proliferation of the epithelial cells in the gastric antrum, incisura, and body mucosa were significantly higher in patients with $H$. pylori infection than in those without infection. These findings suggest that significantly increased cell proliferation and apoptosis exist simultaneously in the process of H. pylori infection, which is associated with the process of antralization. Moreover, the authors reported that $\mathrm{Ki}-$ 67 (a biomarker for cell proliferation) and Bcl-2 expression was 
increased, whereas Bax expression was decreased in the presence of atrophic gastritis and intestinal metaplasia, ${ }^{40}$ further supporting the hypothesis that the balance between apoptosis and proliferation is altered (i.e. in favor of proliferation) in precancerous lesions, leading to increased risk of developing gastric carcinoma.

H. pylori infection is likely to interfere with the balance of cell proliferation and apoptosis by stimulating stem cells, as a previous study found that $H$. pylori infection stimulates the expression of mast cell growth factor (stem cell factor, SCF) in gastric mucosal cells, ${ }^{41}$ thus promoting the proliferation and differentiation of stem cells in gastric mucosa. Gastric stem cells are known to play an important role in glandular regeneration and carcinogenesis of gastric cancer. ${ }^{42-44}$ At present, most researchers believe that gastric stem cells capable of inducing glandular adaptation mainly exist in the isthmus of gastric gland. ${ }^{42,43,45-47}$ Engevik et al. ${ }^{48}$ found that SPEM hardly occurred in old-age healthy mice, but was induced in oldage mice after the organ transplantation of gastric tissues from the younger mice, suggesting that SPEM-related stem cells are probably derived from the gastric tissue. Matsuo et al. $^{46}$ discovered that isthmic stem cells were the main stem cells for induction of foveolar hyperplasia and antralization in the gastric corpus in eR1CreERT2 and Rosa-LSL-td Tomato mouse models, which can be used to cultivate organoids in vitro. ${ }^{46}$ Nam et al. ${ }^{49}$ found that SPEM was induced by DMP-777, L-635 and H. felis infection in mice, and which evolved from differentiated chief cells. The authors proposed that mature gastric chief cells are able to act as cryptic progenitors and reacquire proliferative capacity in the presence of mucosal injury and inflammation. However, these researchers also showed that in Lgr5-EGFP-IRES-Cre ERT2/+ mice, Lgr-5-expressing chief cells were not the major stem cells for SPEM ${ }^{50}$; although, they were present along the lesser curvature of the gastric oxyntic mucosa. Whether these cells play a role in the subsequent deterioration after antralization still needs to be elucidated.

Many gene expression pathways and biological factors have been demonstrated to be involved in the process of $H$. pylori-induced antralization or SPEM and the subsequent carcinogenesis. Scotti et al. ${ }^{51}$ found that L-asparaginase of $H$. pylori interferes with the cell cycle of epithelial cells and alters the normal balance between cell proliferation and apoptosis. Ishii et al. ${ }^{52}$ found that loss of IL-6-mediated activation of signal transduction and activator of transcription 3 (STAT3) signaling significantly reduced the incidence of epithelial cell proliferation, atrophy and metaplasia in $H$. pylori infected mice, and that the inhibition of STAT3 significantly reduced the expression level of the antralization-associated marker TFF2, indicating that the STAT3 signal plays an important role in $H$. pylori-induced antralization or SPEM and gastric carcinogenesis. Huang et al. ${ }^{14}$ found that $H$. pylori-induced inflammation leads to subclonal mutation, DNA methylation and telomere length changes, thus promoting the development of intestinal metaplasia in the gastric mucosa of infected patients and suggesting that antralization may also be related to the above-mentioned changes.

In addition, other pathways, such as Notch signal, Wnt signal, epidermal growth factor signal, transforming growth factor- $\beta$ signal and bone morphogenetic protein signal, have also been found to play an important role in the proliferation of stem cells and may be involved in the process of $H$. pylori-induced antralization or SPEM. ${ }^{43,53,54}$ It is believed that these biological factors promote gastric stem cells to differentiate into neck mucinous cells and endocrine cells, which makes them more similar in the physiological characteristics of antral glands, until they are completely "antralized" (or covered by SPEM). However, antralization or SPEM does not necessarily develop further to more serious precancerous lesions, such as atrophic gastritis, intestinal metaplasia, dysplasia, or atypical hyperplasia; it may, however, further develop into more serious lesions in the inflammatory environment or may regress in the absence of inflammation. ${ }^{55}$ Indeed, Weis et al. ${ }^{55}$ found that SPEM with inflammation in mice expressed multiple intestinal transcription factors, such as cystic fibrosis transmembrane conductance regulator, similar to the profile of specific transcription factors for intestinal metaplasia in humans, suggesting that inflammation could promote the development of SPEM to intestinal metaplasia. It is, thus, likely that $H$. pylori infection induces chronic inflammation, leading to further progress of antralization (or SPEM) towards atrophic gastritis and intestinal metaplasia. Many inflammatory factors, such as IL- $1 \beta$, TNF- $\alpha$ and IL-4, have been found to be significantly increased in the course of $H$. pylori infection and to play an important role in $H$. pylori-induced SPEM. ${ }^{50}$ A previous study showed that macrophages were the main cells that induce the inflammatory response through IL-1 $\beta$ and play an important role in SPEM and the subsequent deterioration process. ${ }^{56}$

A few studies have reported $H$. pylori-associated changes in gastrointestinal microbiota. Ge et al. ${ }^{57}$ reported that the bacterial composition in the gastrointestinal tract of C57BL/6 (B6) mice changed significantly after $H$. pylori colonization. The investigators also observed that the colonization ability of $H$. pylori was different between C57BL/6 (B6) mice obtained from different laboratories. Accordingly, H. pylori-infected mice from Jackson Laboratory had decreased abundance of Bifidobacteriaceae (stomach, colon and feces), Anaeroplasmataceae (stomach and feces), Clostridiaceae (stomach), Coribacteriaceae (colon), and Turicibacteriaceae (feces). H. pylori-infected mice from Taconic Sciences had increased abundance of Helicobacteraceae (stomach), Lactobacillaceae (colon and feces), and Mogibacteriaceae (feces). Maldonado-Contreras et al. ${ }^{58}$ found that the gastric microbiota in $H$. pylori-negative patients had greater abundance of Actinobacteria and Firmicutes, whereas H. pylori-positive subjects had greater abundance of Proteobacteria and Acidobacteria. Gao et al..$^{59}$ showed that Bacteroidetes, Firmicutes and Proteobacteria in fecal microbiota were significantly correlated with $H$. pylori infection. These findings indicate that $H$. pylori colonization may affect the structure and composition of gastrointestinal bacteria in humans, and thus in the gut microbiota.

It is believed that $H$. pylori infection induces antralization of the incisura and body and consequently affects gastric acid secretion, resulting in hypohydrochloria. The anhydrochloric environment is in favor of many bacteria, leading to changes in the microbiota of the stomach. In the meantime, H. pylori-induced hypohydrochloria also forms an unfriendly or hostile living environment for $H$. pylori. ${ }^{60}$ The abundance of $H$. pylori gradually decreases or even disappears following the development of precancerous lesions. ${ }^{61,62}$ This phenomenon indicates that H. pylori infection per se is not necessarily required to contribute to the subsequent development of gastric cancer in the presence of precancerous lesions. Then, what causes the further development of more severe precancerous lesions and gastric cancer after the disappearance of $H$. pylori?

One of the potential carcinogenic mechanisms is a series of pathological and inflammatory reactions derived from the original H. pylori infection, i.e. H. pylori further influencing the progression of gastric cancer from precancerous lesions after its disappearance, indirectly through these reactions. ${ }^{62}$ Another possible carcinogenic mechanism is altered gastric microbiota, i.e. some gastrointestinal bacteria during $H$. pylori infection or after its disappearance acting as an "accomplice or successor" of $H$. pylori and playing an important carcinogenic role after $H$. pylori disappearance. Indeed, it has also been demonstrated that there are significant differences in the composition of gastrointestinal microbiota among patients with nonatrophic gastritis, intestinal metaplasia, and gastric cancer. ${ }^{63}$ This suggests that gut microbiota, especially those in the stomach, may play an important role in the progression of $H$. pylori-related 


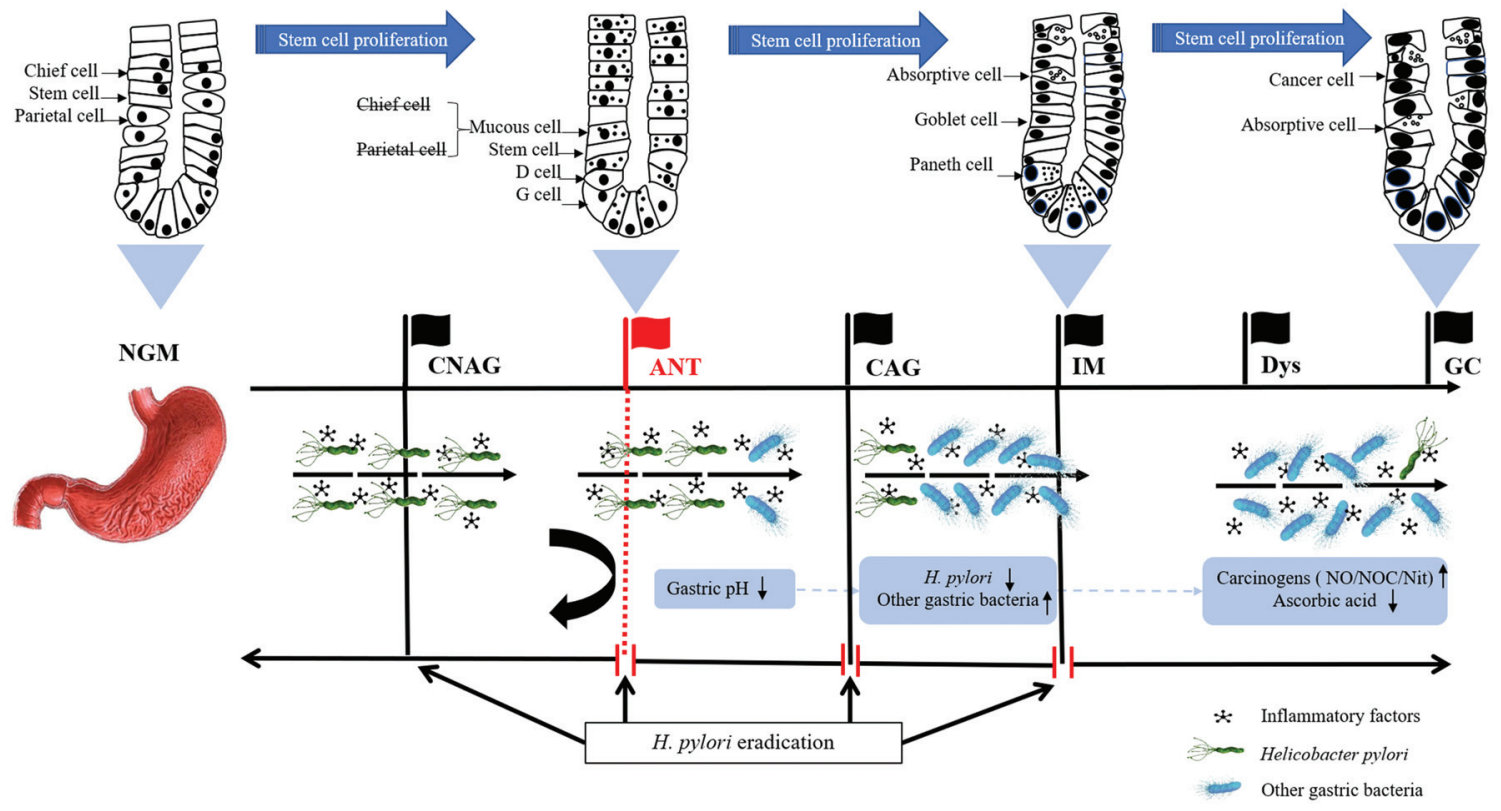

Fig. 2. Proposed role of Helicobacter pylori-induced antralization in gastric carcinogenesis. H. pylori infection leads to inflammation in the gastric mucosa and apoptosis of the epithelial cells. The stem cells proliferate and transform into mucous cells and form antral-type mucosa (i.e. antralization). H. pyloriinduced antralization may participate in the development of atrophic gastritis, intestinal metaplasia, dysplasia and early gastric cancer, with the presence of carcinogens and gastric bacteria. H. pylori eradication may reverse antralization and cease the process from antralization to gastric cancer. ANT, antralization; CAG, chronic atrophic gastritis; CNAG, chronic non-atrophic gastritis; Dys, dysplasia; GC, gastric cancer; IM, intestinal metaplasia; NGM, normal gastric mucosa.

gastric lesions, including antralization, atrophic gastritis, intestinal metaplasia and gastric cancer; although, more experimental evidence is required to confirm the hypothesis. The gastric microbiota is known to cause gastric cancer through chronic inflammation, immune regulation, and microbial metabolites. ${ }^{64}$ Therefore, it is conceivable that chronic $H$. pylori infection causes an alteration in gastric or gut microbiota, which plays a critical role in gastric carcinogenesis of $H$. pylori-induced antralization during $H$. pylori infection and in the "post-H. pylori" era.

Based on the evidence and findings above, we postulate that in the persistence of $H$. pylori infection the stem cells in the proliferative zone at the proximal stomach, especially the gastric incisura (where acid-secreting gastric body type glands are normally predominant), shift to generate antral-type glands that produce gastric mucins involved in defense and repair mechanisms. ${ }^{16,65}$ Chronic insults by H. pylori infection thus lead to the replacement of body-type mucosa by antral-type mucosa at the proximal stomach. Antral-type mucosa is believed to be more predisposed to the development of gastric precancerous lesions, including atrophic gastritis, intestinal metaplasia and dysplasia, compared with bodytype mucosa. ${ }^{16}$ In addition, increased cell proliferation stimulated by persistent $H$. pylori infection presumably facilitates the development of precancerous lesions and intestinal-type gastric carcinoma in antralized mucosa. ${ }^{36-38}$ Thus, antralization (or SPEM) may play a critical role in gastric carcinogenesis, and it may also be a reversible step (Fig. 2). ${ }^{17}$

Diagnosis of antralization and its implications in clinical practice

As a reversible pathological step occurring immediately prior to the "point-of no-return" precancerous lesion development during gastric carcinogenesis, antralization can be used as an important indicator for screening individuals with high-risk of gastric cancer for early intervention. Currently, the only diagnostic method of antralization is histological examination of gastric tissue biopsies, which can be used as the golden standard for diagnosis of antralization. The diagnostic criterion is the change of gastric mucosa from transitional-type or body-type to antral-type, histologically characterized by the loss of parietal cells and the substitution proliferation of mucus neck cells and endocrine cells. ${ }^{16}$

There are some critical issues for biopsy-based diagnosis of antralization. First, histological examination of gastric biopsies is associated with upper endoscopy, which is an invasive procedure that is not feasible for screening a population on large scale. Second, previous studies have demonstrated that antralization often occurs at the gastric incisura, and then gradually extends up to the gastric body or even the fundus. ${ }^{20}$ Due to the importance of the gastric incisura in the pathological changes, including gastric inflammation and precancerous lesions, the updated Sydney system suggests that endoscopists take four biopsy specimens, two each from the gastric antrum and body, respectively, with an additional biopsy from the incisura angularis. ${ }^{66}$ However, this protocol is hardly followed in clinical practice, particularly in developing countries, including China where the upper endoscopic workload is huge and patients usually cannot afford the cost for histological examination of five biopsy specimens. In addition, histological examination is a tedious procedure that may take days to produce results.

Clinically, the combination of magnifying endoscopy with narrow band imaging (commonly known as ME-NBI) may be used to detect antralization, although its performance needs to be further validated. Li et al. ${ }^{67}$ reported that under ME-NBI, the body-type mucosa presents as a honeycomb-like subepithelial capillary network (dark brown), with an oval dark glandular opening in the 


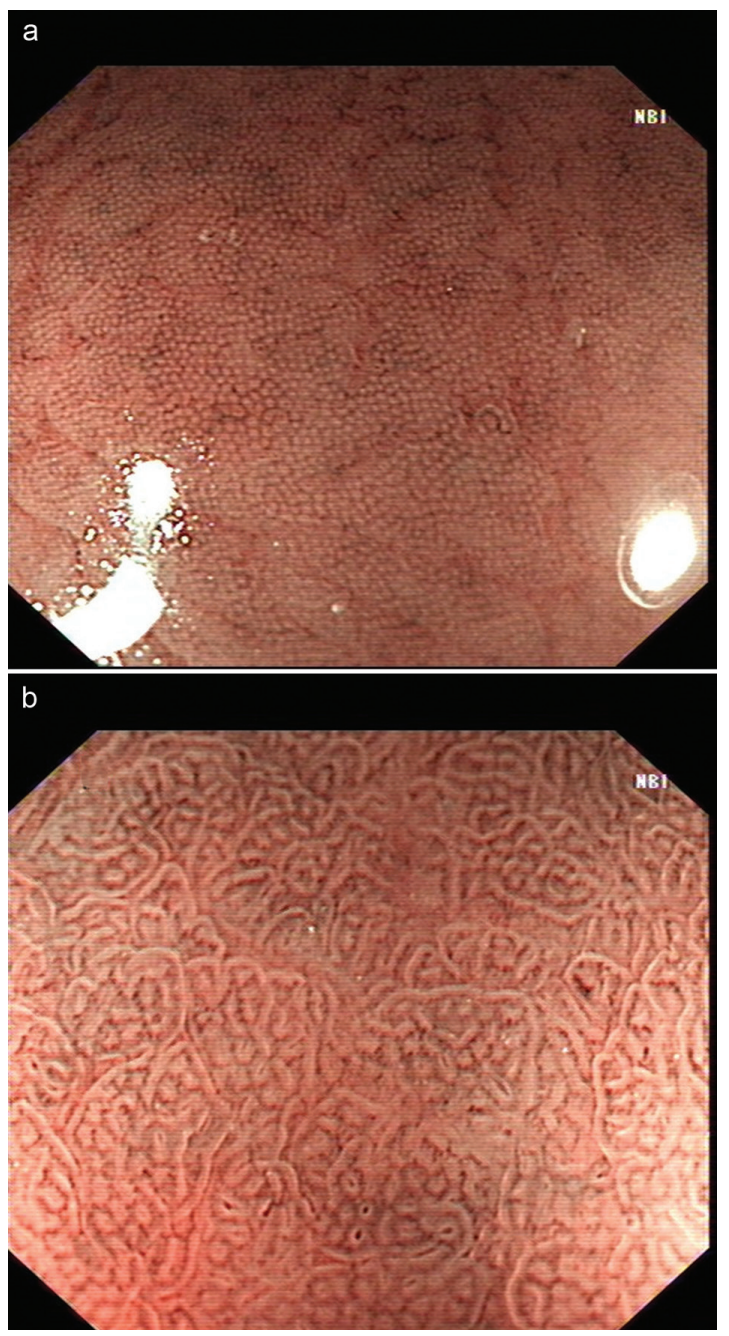

Fig. 3. Normal gastric mucosa. (a) Body-type mucosa under ME-NBI. (b) Antral-type mucosa under ME-NBI. The pictures were provided by Department of Digestive Endoscopy, the First Affiliated Hospital of Guangdong Pharmaceutical University, Guangzhou, China. ME-NBI, magnifying endoscopy with narrow band imaging.

center and interspersed with spider-like collecting veins (Fig. $3 a)$, whereas the antral-type mucosa presents as a curly or wavy subepithelial capillary network, with the spider-like collecting veins being rarely observed (Fig. 3b). Therefore, antralization is considered when the appearance of antral-type mucosa is shown in gastric incisura, body, and fundus under ME-NBI. However, traditional endoscopy is still an invasive operation, and thus not appropriate for screening in the population. Therefore, search for surrogate non-invasive methodologies, such as serological tests of biomarkers, that are simple, rapid and cheap, and which can accurately diagnose antralization of the proximal stomach, are required.

Several biomarkers have been explored for their ability to diagnose antralization. For example, the regenerated antral-like mucosa is often characterized by the antral glands; ${ }^{16}$ moreover, the TFF2 and mucin 6 (MUC6) expressed in antral glands are specific indicators of antralization. ${ }^{65}$ Sakai et al. ${ }^{68}$ reported co-expression of MUC6 and pepsinogen I (PGI) as a characteristic feature of the pseudopyloric gland. The authors also demonstrated that the pancreatic duodenal homeobox 1 (PDX1), one of ParaHox gene family members, was expressed in antralization and intestinal metaplasia but not in advanced lesions. Moreover, they also found that the ratio of MUC6 to MUC5AC was higher in patients with antralization and lower in patients with intestinal metaplasia. Xia et $a l .{ }^{40}$ found that in the antralized mucosa, chronic atrophic gastritis and intestinal metaplasia mucosa at the gastric incisura, cell proliferation and $\mathrm{Bcl}-2$ increased, while Bax expression decreased. Moreover, this group of researchers also demonstrated that the expression of PDX1, NK6 homeobox 1 (NKX6.1) and paired box 6 (PAX6) was lower in the cytoplasmic chamber of antralized mucosa with $H$. pylori infection than that in transitional-type or body-type mucosa; whereas, caudal-related homeobox transcription factor 2 (CDX2) expression was up-regulated in the intestinal metaplasia group. ${ }^{69}$ Therefore, biological factors like TFF2 and MUC6 are specifically expressed in the antralized mucosa, while other biological factors like MUC5AC, PAX6, PDX1, PG I, BAX, NKX6.1, BCl-2 and Ki-67 and inflammatory markers like IL-1 $\beta$, TNF- $\alpha$, IL-4 and macrophages can also be used to assist in the diagnosis of antralization. ${ }^{20,65-69}$ However, a complete prediction system that is based on these specific and general biological factors and evaluates the pathological state of the gastric mucosa for antralization is required to be established and used as an important index for screening and diagnosis of precancerous lesions and early gastric cancer.

Over the past decades, the biological markers for precancerous lesions, such as atrophic gastritis, intestinal metaplasia and early gastric cancer, have been explored extensively, producing some conflicting results. For example, Urita et al. ${ }^{70}$ reported that the observed lower PG I/II ratios and lower PG I values could be used to identify intestinal metaplasia. This contrasted with the report from Stemmermann et al. ${ }^{71}$ that there was no notable specificity of PG I and PG I/PG II in predicting gastric cancer. Another study showed that a gastric cancer prediction tool based on a panel of serum biomarkers including PG I, PG II, gastrin-17 (g-17) and anti-H. pylori IgG antibody had good performance in identifying high-risk patients. ${ }^{72}$ Huang et al..$^{73}$ further found that serum TFF3 levels were significantly higher in patients with gastric cancer than in their control group, and suggested that the combined detection of serum PG and TFF3 could improve the efficacy of gastric cancer screening. Similarly, Aikou et al. ${ }^{74}$ found that serum TFF3 levels in patients with gastric cancer were significantly higher than those in the normal group. In addition, the serum levels of TFF1 and TFF2 in patients with differentiated gastric cancer were lower than in those with undifferentiated gastric cancer, and suggesting that this feature may reflect the replacement of foveolar hyperplasia and SPEM with intestinal metaplasia. Finally, other researchers found that TFF2 can predict the severity of SPEM in familial relatives of gastric cancer patients with corpus gastritis index. ${ }^{75}$

Based on the above findings and data, we propose a series of factors that are potential biomarkers specific for antralization of the proximal stomach, as well as intestinal metaplasia and gastric cancer, according to Correa's cascade, in order to provide ideas for further exploring noninvasive methods for the diagnosis of gastric antralization (Table 1).

\section{Future research directions}

As mentioned above, $H$. pylori-induced antralization may play a key role in the process of gastric carcinogens. Future research will focus on the specific mechanisms by which it develops into gastric 
Table 1. Biomarkers of antralization, intestinal metaplasia and gastric cancer

\begin{tabular}{llll}
\hline \multirow{2}{*}{ Biomarker } & \multicolumn{2}{c}{ Change in the expression } & Gastric cancer \\
\cline { 2 - 4 } & Antralization & Intestinal metaplasia & Down \\
\hline TFF1 & NR & Down & Down \\
TFF2 & Up* & Down & Up* \\
TFF3 & NR & Up & Down \\
MUC6 & Up* & NR & NR \\
MUC6:MUC5AC & Up & Down & Up \\
PDX1 & Up & Up & Up \\
CDX2 & NR & Up* & Down \\
PGI & Down & Down & Up \\
PGII & Up & Up & Down \\
PGI/PGI & Down & Down & Up \\
BCl-2 & Up & Up & Down \\
Bax & Down & Down & Up \\
Ki-67 & Up & Up & Down \\
PAX6 & Down & Down & Down \\
NKX6.1 & Down & Down & \\
\hline
\end{tabular}

*Specific alteration. NR, not reported.

cancer. In addition, a noninvasive method that specifically identifies antralization is currently lacking, and thus further investigation is required to develop a simple, noninvasive diagnostic method specifically for the detection of antralization in order to conveniently identify high-risk gastric cancer patients.

\section{Conclusions}

H. pylori-induced antralization (or SPEM) may be an initiating and reversible stage of gastric carcinogenesis. ${ }^{17}$ Identification of antralization would help to develop an early intervention (e.g. eradication of $H$. pylori infection) to cease or even reverse the process toward development of gastric cancer, and more importantly to identify patients with high-risk for precancerous lesions so that gastric cancer can be detected earlier. Currently, the "gold standard" for diagnosing antralization is pathology, which is invasive and time consuming. Thus, a noninvasive and more convenient diagnostic method is urgently required.

\section{Acknowledgments}

We would like to thank Drs. Ning Yang and Zhiliang Deng, from the Departments of Digestive Endoscopy and Pathology, the First Affiliated Hospital of Guangdong Pharmaceutical University, for providing the endoscopic and histological photos presented in this manuscript.

\section{Conflict of interest}

The authors have no conflict of interests related to this publication.

\section{Author contributions}

Writing the main part of the article (ZNY), providing some figure and related information (RZ), providing revision suggestions $(\mathrm{XXH})$, guiding writing and revising the article (HHX).

\section{References}

[1] Bray F, Ferlay J, Soerjomataram I, Siegel RL, Torre LA, Jemal A. Global cancer statistics 2018: GLOBOCAN estimates of incidence and mortality worldwide for 36 cancers in 185 countries. CA Cancer J Clin 2018;68(6):394-424. doi:10.3322/caac.21492.

[2] Schistosomes, liver flukes, Helicobacter pylori. IARC Working Group on the Evaluation of Carcinogenic Risks to Humans. Lyon, 7-14 June 1994. IARC Monogr Eval Carcinog Risks Hum 1994;61:177-241.

[3] Doorakkers E, Lagergren J, Engstrand L, Brusselaers N. Eradication of Helicobacter pylori and gastric cancer: a systematic review and meta-analysis of cohort studies. J Natl Cancer Inst 2016;108(9):djw132. doi:10.1093/jnci/djw132.

[4] Laks S, Meyers MO, Kim HJ. Surveillance for gastric cancer. Surg Clin North Am 2017;97(2):317-331. doi:10.1016/j.suc.2016.11.007.

[5] Correa P, Haenszel W, Cuello C, Zavala D, Fontham E, Zarama G, et al. Gastric precancerous process in a high risk population: cross sectional studies. Cancer Res 1990;50(15):4731-4736. doi:10.1097/00002820199008000-00007.

[6] Chen HN, Wang Z, Li X, Zhou ZG. Helicobacter pylori eradication cannot reduce the risk of gastric cancer in patients with intestinal metaplasia and dysplasia: evidence from a meta-analysis. Gastric Cancer 2016;19(1):166-175. doi:10.1007/s10120-015-0462-7.

[7] Ito M, Haruma K, Kamada T, Mihara M, Kim S, Kitadai Y, et al. Helicobacter pylori eradication therapy improves atrophic gastritis and intestinal metaplasia: a 5-year prospective study of patients with atrophic gastritis. Aliment Pharmacol Ther 2002;16(8):1449-1456. doi:10.1046/j.1365-2036.2002.01311.x.

[8] Hwang YJ, Kim N, Lee HS, Lee JB, Choi YJ, Yoon H, et al. Reversibility of 
atrophic gastritis and intestinal metaplasia after Helicobacter pylori eradication - a prospective study for up to 10 years. Aliment Pharmacol Ther 2018;47(3):380-390. doi:10.1111/apt.14424.

[9] Vannella L, Lahner E, Bordi C, Pilozzi E, Di Giulio E, Corleto VD, et al. Reversal of atrophic body gastritis after $\mathrm{H}$. pylori eradication at longterm follow-up. Dig Liver Dis 2011;43(4):295-299. doi:10.1016/j. dld.2010.10.012.

[10] Kilciler G, Polat Z, Uygun A, Kantarcıoğlu M, Gülşen M. The effect of Helicobacter Pylori eradication on atrophic gastritis and intestinal metaplasia. J Clin Anal Med 2011;2(1):17-20. doi:10.4328/ JCAM.191.

[11] Annibale B, Di Giulio E, Caruana P, Lahner E, Capurso G, Bordi C, et al. The long-term effects of cure of Helicobacter pylori infection on patients with atrophic body gastritis. Aliment Pharmacol Ther 2002;16(10):1723-1731. doi:10.1046/j.1365-2036.2002.01336.x.

[12] Mera RM, Bravo LE, Camargo MC, Bravo JC, Delgado AG, RomeroGallo J, et al. Dynamics of Helicobacter pylori infection as a determinant of progression of gastric precancerous lesions: 16-year followup of an eradication trial. Gut 2017;67(7):1239-1246. doi:10.1136/ gutjnl-2016-311685.

[13] Salih BA, Abasiyanik MF, Saribasak H, Huten O, Sander E. A follow-up study on the effect of Helicobacter pylori eradication on the severity of gastric histology. Dig Dis Sci 2005;50(8):1517-1522. doi:10.1007/ s10620-005-2871-7.

[14] Huang KK, Ramnarayanan K, Zhu F, Srivastava S, Xu C, Tan ALK, et al. Genomic and epigenomic profiling of high-risk intestinal metaplasia reveals molecular determinants of progression to gastric cancer. Cancer Cell 2018;33(1):137-150. doi:10.1016/j.ccell.2017.11.018.

[15] den Hoed CM, Holster IL, Capelle LG, de Vries AC, den Hartog B, Ter Borg $\mathrm{F}$, et al. Follow-up of premalignant lesions in patients at risk for progression to gastric cancer. Endoscopy 2013;45(4):249-256. doi:1 0.1055/s-0032-1326379.

[16] Xia HH, Kalantar J, Ma Wyatt J, Adams S, Cheung K, NJ Talley. Helicobacter pylori associated antralization of proximal gastric mucosa is linked to an increased risk of development of intestinal metaplasia. Gastroenterology 1998;114(Suppl 1):A355. doi:10.1016/S00165085(98)81359-0.

[17] Xia HH, Lam SK, Wong WM, Hu WH, Lai KC, Wong SH, et al. Antralization at the edge of proximal gastric ulcers: does Helicobacter pylori infection play a role? World J Gastroenterol 2003;9(6):1265-1269. doi:10.1046/j.1365-2982.2003.00408.x.

[18] Schmidt PH, Lee JR, Joshi V, Playford RJ, Poulsom R, Wright NA, et al. Identification of a metaplastic cell lineage associated with human gastric adenocarcinoma. Lab Invest 1999;79(6):639-646. doi:10.1121/1.424682.

[19] Rubio CA, Jaramillo E, Suzuki G, Lagergren P, Nesi G. Antralization of the gastric mucosa of the incisura angularis and its gastrin expression. Int J Clin Exp Pathol 2009;2(1):65-70. doi:10.3109/14992020903085735.

[20] Xia HH, Kalantar JS, Talley NJ, Wyatt JM, Adams S, Chueng K, et al. Antral-type mucosa in the gastric incisura, body, and fundus (antralization): a link between Helicobacter pylori infection and intestinal metaplasia? Am J Gastroenterol 2000;95(1):114-121. doi:10.1111/ j.1572-0241.2000.01609.x.

[21] Nookaew I, Thorell K, Worah K, Wang S, Hibberd ML, Sjövall H, et al. Transcriptome signatures in Helicobacter pylori-infected mucosa identifies acidic mammalian chitinase loss as a corpus atrophy marker. BMC Med Genomics 2013;6(1):41. doi:10.1186/1755-8794-6-41.

[22] Hebbelr R. The topography of chronic gastritis in otherwise normal stomachs. Am J Pathol 1949;25(1):125-141. doi:10.1016/00029416(49)90089-5.

[23] Sloan JM, Buchanan KD, McFarland RJ, Titterington P, Sandford JC. A histological study of the effect of chronic gastritis on gastrin cell distribution in the human stomach. J Clin Pathol 1979;32(3):201-207. doi:10.1136/jcp.32.3.201.

[24] Nielsen HO, Lauritsen K, Christiansen LA. The human stomach after antrectomy. A study of the type of epithelium, occurrence of gastrin-producing cells, and basal serum gastrin. Scand J Gastroenterol 1981;16(3):353-356. doi:10.3109/00365528109181980.

[25] Green PH, Gold RP, Marboe CC, Weinberg LM, Goldfarb JP, Brasitus TA. Chronic erosive gastritis: clinical, diagnostic, and pathological features in nine patients. Am J Gastroenterol 1982;77(8):543-547. doi:10.1111/j.1572-0241.1982.tb04881.x.

[26] Goldenring JR. Pyloric metaplasia, pseudopyloric metaplasia, ulcerassociated cell lineage and spasmolytic polypeptide-expressing metaplasia: reparative lineages in the gastrointestinal mucosa. J Pathol 2018;245(2):132-137. doi:10.1002/path.5066.

[27] Hattori T, Helpap B, Gedigk P. Regeneration of endocrine cells in the stomach. Virchows Arch B Cell Pathol Incl Mol Pathol 1982;38(3):283290. doi:10.1007/BF02892823.

[28] Hunt TE. Regeneration of the gastric mucosa in the rat. Anat Rec 1958;131(2):193-211. doi:10.1002/ar.1091310205.

[29] van der Gaag I. The histological appearance of peroral gastric biopsies in clinically healthy and vomiting dogs. Can J Vet Res 1988;52(1):6774. doi:10.1080/03079458808436513.

[30] Whitehead R, Truelove SC, Gear MW. The histological diagnosis of chronic gastritis in fibreoptic gastroscope biopsy specimens. J Clin Pathol 1972;25(1):1-11. doi:10.1136/jcp.25.1.1.

[31] Yamaguchi H, Goldenring JR, Kaminishi M, Lee JR. Identification of spasmolytic polypeptide expressing metaplasia (SPEM) in remnant gastric cancer and surveillance postgastrectomy biopsies. Dig Dis Sci 2002;47(3):573-578. doi:10.1023/a:1017920220149.

[32] Weis VG, Goldenring JR. Current understanding of SPEM and its standing in the preneoplastic process. Gastric Cancer 2009;12(4):189-197. doi:10.1007/s10120-009-0527-6.

[33] Sgouras D, Tegtmeyer N, Wessler S. Activity and functional importance of Helicobacter pylori virulence factors. Adv Exp Med Biol 2019;doi:10.1007/5584_2019_358.

[34] Sáenz JB, Vargas N, Mills JC. Tropism for spasmolytic polypeptide-expressing metaplasia allows Helicobacter pylori to expand Its intragastric niche. Gastroenterology 2019;156(1):160-174.e7. doi:10.1053/j. gastro.2018.09.050.

[35] Sáenz JB, Mills JC. Acid and the basis for cellular plasticity and reprogramming in gastric repair and cancer. Nat Rev Gastroenterol Hepatol 2018;15(5):257-273. doi:10.1038/nrgastro.2018.5.

[36] Preston-Martin S, Pike MC, Ross RK, Jones PA, Henderson BE. Increased cell division as a cause of human cancer. Cancer Res 1990;50(23):7415-7421. doi:10.1038/nrgastro.2018.5.

[37] Correa P. Helicobacter pylori and gastric carcinogenesis. Am J Surg Pathol 1995;19(suppl 1):S37-S43. doi:10.1007/s00535-009-0014-1.

[38] Xia HH-X, Talley NJ. Apoptosis in gastric epithelium induced by Helicobacter pylori infection: Implications in gastric carcinogenesis. Am J Gastroenterol 2001;96(1):16-26. doi:10.1111/j.15720241.2001.03447.x.

[39] Xia HH, Wong BC, Zhang GS, Yang Y, Wyatt JM, Adams S, et al. Antralization of gastric incisura is topographically associated with increased gastric epithelial apoptosis and proliferation, but not with CagA seropositivity. J Gastroenterol Hepatol 2004;19(11):1257-1263. doi:10.1111/j.1440-1746.2004.03489.x.

[40] Xia HH, Zhang GS, Talley NJ, Wong BC, Yang Y, Henwood C, et al. Topographic association of gastric epithelial expression of Ki-67, Bax and $\mathrm{Bcl}-2$ with antralization in the gastric incisura, body, and fundus. Am J Gastroenterol 2002;97(12):3023-3031. doi:10.1111/j.15720241.2002.07120.x.

[41] Bamba N, Nakajima S, Andoh A, Bamba M, Sugihara H, Bamba T, et al. Stem cell factor expressed in human gastric mucosa in relation to mast cell increase in Helicobacter pylori-infected gastritis. Dig Dis Sci 2002;47(2):274-282. doi:10.1023/a:1013701618079.

[42] Singh SR. Gastric cancer stem cells: a novel therapeutic target. Cancer Lett 2013;338(1):110-119. doi:10.1016/j.canlet.2013.03.035.

[43] Flanagan DJ, Austin CR, Vincan E, Phesse TJ. Wnt signalling in Gastrointestinal epithelial stem cells. Genes (Basel) 2018;9(4):178. doi:10.3390/genes9040178.

[44] Takaishi S, Okumura T, Tu S, Wang SS, Shibata W, Vigneshwaran R, et al. Identification of gastric cancer stem cells using the cell surface marker CD44. Stem Cells 2009;27(5):1006-1020. doi:10.1002/ stem.30.

[45] Takaishi S, Okumura T, Wang TC. Gastric cancer stem cells. J Clin Oncol 2008;26(17):2876-2882. doi:10.1200/JCO.2007.15.2603.

[46] Matsuo J, Kimura S, Yamamura A, Koh CP, Hossain MZ, Heng DL, et al. Identification of stem cells in the epithelium of the stomach corpus and antrum of mice. Gastroenterology 2017;152(1):218-231. doi:10.1053/j.gastro.2016.09.018. 
[47] Xu G, Shen J, Ou Yang X, Sasahara M, Su X. Cancer stem cells: the 'heartbeat' of gastric cancer. J Gastroenterol 2013;48(7):781-797. doi:10.1007/s00535-012-0712-y.

[48] Engevik AC, Feng R, Choi E, White S, Bertaux-Skeirik N, Li J, et al. The development of spasmolytic polypeptide TFF2-expressing metaplasia (SPEM) during gastric repair is absent in the aged stomach. Cell Mol Gastroenterol Hepatol 2016;2(5):605-624. doi:10.1016/j. jcmgh.2016.05.004.

[49] Nam KT, Lee HJ, Sousa JF, Weis VG, O'Neal RL, Finke PE, et al. Mature chief cells are cryptic progenitors for metaplasia in the stomach. Gastroenterology 2010;139(6):2028-2037. doi:10.1053/j.gastro.2010.09.005.

[50] Nam KT, O'Neal RL, Coffey RJ, Finke PE, Barker N, Goldenring JR. Spasmolytic polypeptide-expressing metaplasia (SPEM) in the gastric oxyntic mucosa does not arise from Lgr5-expressing cells. Gut 2012;61(12):1678-1685. doi:10.1136/gutjnl-2011-301193.

[51] Scotti C, Sommi P, Pasquetto MV, Cappelletti D, Stivala S, Mignosi P, et al. Cell-cycle inhibition by Helicobacter pylori L-asparaginase. PLoS One 2010;5(11):e13892. doi:10.1371/journal.pone.0013892.

[52] Ishii Y, Shibata W, Sugimori M, Kaneta Y, Kanno M, Sato T, et al. Activation of signal transduction and activator of transcription 3 signaling contributes to Helicobacter-associated gastric epithelial proliferation and inflammation. Gastroenterol Res Pract 2018;2018:9050715. doi:10.1155/2018/9050715.

[53] Gao D, Vahdat LT, Wong S, Chang JC, Mittal V. Microenvironmental regulation of epithelial-mesenchymal transitions in cancer. Cancer Res 2012;72(19):4883-4889. doi:10.1158/0008-5472.CAN-12-1223.

[54] Barros R, Freund JN, David L, Almeida R. Gastric intestinal metaplasia revisited function and regulation of CDX2. Trends Mol Med 2012;18(9):555-563. doi:10.1016/j.molmed.2012.07.006.

[55] Weis VG, Sousa JF, LaFleur BJ, Nam KT, Weis JA, Finke PE, et al. Heterogeneity in mouse spasmolytic polypeptide-expressing metaplasia lineages identifies markers of metaplastic progression. Gut 2013;62(9):1270-1279. doi:10.1136/gutjnl-2012-302401.

[56] Petersen CP, Weis VG, Nam KT, Sousa JF, Fingleton B, Goldenring JR. Macrophages promote progression of spasmolytic polypeptide-expressing metaplasia after acute loss of parietal cells. Gastroenterology 2014;146(7):1727-1738. doi:10.1053/j.gastro.2014.02.007.

[57] Ge Z, Sheh A, Feng Y, Muthupalani S, Ge L, Wang C, et al. Helicobacter pylori-infected C57BL6 mice with different gastrointestinal microbiota have contrasting gastric pathology, microbial and host immune responses. Scientific Reports 2018;8(1):8014. doi:10.1038/s41598018-25927-2.

[58] Maldonado-Contreras A, Goldfarb KC, Godoy-Vitorino F, Karaoz U, Contreras M, Blaser MJ, et al. Structure of the human gastric bacterial community in relation to Helicobacter pylori status. ISME J 2011;5(4):574-579. doi:10.1038/ismej.2010.149.

[59] Gao JJ, Zhang Y, Gerhard M, Mejias-Luque R, Zhang L, Vieth M, et al. Association between gut microbiota and Helicobacter pylori-related gastric lesions in a high-risk population of gastric cancer. Front Cell Infect Microbiol 2018;8:202. doi:10.3389/fcimb.2018.00202.

[60] Xia HH, Talley NJ. Helicobacter pylori infection, atrophic gastritis and reflux esophagitis: an unexplored triangle. Am J Gastroenterol 1998;93(3):394-400. doi:10.1111/j.1572-0241.1998.00394.x.
[61] Kokkola A, Rautelin H, Puolakkainen P, Sipponen P, Färkkilä M, Haapiainen $\mathrm{R}$, et al. Positive result by serology indicates active Helicobacter pylori infection in patients with atrophic gastritis. J Clin Microbiol 1998;36(6):1808-1810.

[62] Polk DB, Peek RM Jr. Helicobacter pylori: gastric cancer and beyond. Nat Rev Cancer 2010;10(6):403-414. doi:10.1038/nrc2857.

[63] Malfertheiner P, Megraud F, O'Morain CA, Gisbert JP, Kuipers EJ, Axon AT, et al. Management of Helicobacter pylori infection-the Maastricht V/Florence Consensus Report. Gut 2017;66(1):6-30. doi:10.1136/ gutjnl-2016-312288.

[64] Meng C, Bai C, Brown TD, Hood LE, Tian Q. Human gut microbiota and gastrointestinal cancer. Genomics Proteomics Bioinformatics 2018;16(1):33-49. doi:10.1016/j.gpb.2017.06.002.

[65] Xia HH, Yang Y, Lam SK, Wong WM, Leung SY, Yuen ST, et al. Aberrant epithelial expression of trefoil family factor 2 and mucin 6 in Helicobacter pylori infected gastric antrum, incisura, and body and its association with antralisation. J Clin Pathol 2004;57(8):861-866. doi:10.1136/jcp.2003.015487.

[66] Stolte M, Meining A. The updated Sydney system: Classification and grading of gastritis as the basis of diagnosis and treatment. Can J Gastroenterol 2001;15(9):591-598. doi:10.1155/2001/367832.

[67] Li HY, Ge ZZ, Fujishiro M, Li XB. Current clinical applications of magnifying endoscopy with narrow band imaging in the stomach. Diagn Ther Endosc 2012;2012:271914. doi:10.1155/2012/271914.

[68] Sakai H, Eishi Y, Li XL, Akiyama Y, Miyake S, Takizawa T, et al. PDX1 homeobox protein expression in pseudopyloric glands and gastric carcinomas. Gut 2004;53(3):323-330. doi:10.1136/gut.2003.026609.

[69] Zhu S, Xia HH, Yang Y, Ma J, Chen M, Hu P, et al. Alterations of gastric homeoprotein expression in Helicobacter pylori infection, incisural antralisation, and intestinal metaplasia. Dig Dis Sci 2009;54(5):9961002. doi:10.1007/s10620-008-0459-8.

[70] Urita Y, Hike K, Torii N, Kikuchi Y, Kanda E, Sasajima M, et al. Serum pepsinogens as a predicator of the topography of intestinal metaplasia in patients with atrophic gastritis. Dig Dis Sci 2004;49(5):795-801. doi:10.1023/b:ddas.0000030091.92379.91.

[71] Stemmermann GN, Samloff IM, Nomura AM, Heilbrun LK. Serum pepsinogens I and II and stomach cancer. Clin Chim Acta 1987;163(2):191-198. doi:10.1016/0009-8981(87)90022-2.

[72] Cai Q, Zhu C, Yuan Y, Feng Q, Feng Y, Hao Y, et al. Development and validation of a prediction rule for estimating gastric cancer risk in the Chinese high-risk population: a nationwide multicentre study. Gut 2019;68(9):1576-1587. doi:10.1136/gutjnl-2018-317556.

[73] Huang Z, Zhang X, Lu H, Wu L, Wang D, Zhang Q, et al. Serum trefoil factor 3 is a promising non-invasive biomarker for gastric cancer screening: a monocentric cohort study in China. BMC Gastroenterol 2014;14:74. doi:10.1186/1471-230X-14-74.

[74] Aikou S, Ohmoto Y, Gunji T, Matsuhashi N, Ohtsu H, Miura H, et al. Tests for serum levels of trefoil factor family proteins can improve gastric cancer screening. Gastroenterology 2011;141(3):837-845 doi:10.1053/j.gastro.2011.05.040.

[75] Kuo HY, Chang WL, Yeh YC, Tsai YC, Wu CT, Cheng HC, et al. Serum level of trefoil factor 2 can predict the extent of gastric spasmolytic polypeptide-expressing metaplasia in the $H$. pylori-infected gastric cancer relatives. Helicobacter 2017;22(1):1-8. doi:10.1111/hel.12320. 